\section{REFERENCES}

I. Pink GH, Brown AD, Studer ML, et al. Pay-for-performance in publicly financed healthcare: some international experience and considerations for Canada. Healthc Pap 2006;6:8-26.

2. Doran T, Fullwood C, Gravelle H, et al. Pay-for-performance programs in family practices in the United Kingdom. NEngl J Med 2006;355:375-84.

3. Rosenthal MB, Frank RG, Li Z, et al. Early experience with pay-for-performance: from concept to practice. JAMA 2005;294:1788-93.

4. Petersen LA, Woodard LD, Urech T, et al. Does pay-for-performance improve the quality of health care? Ann Intern Med 2006;145:265-72.

5. Rosenthal MB, Dudley RA. Pay-for-performance: will the latest payment trend improve care? JAMA 2007;297:740-4.

6. Lindenauer PK, Remus D, Roman S, et al. Public reporting and pay for performance in hospital quality improvement. N Engl J Med 2007;356:486-96.
7. Millett C, Gray J, Saxena S, et al. Impact of a pay-for-performance incentive on support for smoking cessation and on smoking prevalence among people with diabetes. CMAJ 2007;176:1705-10.

8. Agency for Healthcare Research and Quality. National healthcare quality report, 2006. AHRQ Pub no 07-00I3. Available: www.ahrq.gov/qual/nhqro6/nhqro6.htm (accessed 2007 Apr I9).

9. Epstein AM. Pay for performance at the tipping point. NEngl J Med 2007;356:515-7.

Io. Rosenthal MB, Fernandopulle R, Song HR, et al. Paying for quality: providers' incentives for quality improvement. Health Aff (Millwood) 2004;23:127-4I.

Correspondence to: Dr. Chaim M. Bell, St. Michael's Hospital, 30 Bond St., Toronto ON M5B IW8; fax 416 864-5485; bellc@smh.toronto.on.ca

\title{
Encouraging medical students to do research and write papers
}

\section{Michael E. Detsky, Allan S. Detsky}

S ociety has a vested interest in supporting and promoting health care research. Physicians, among other clinical professionals, have an important role to play. In recent years, many have decried the lack of opportunities for physicians to perform research. ${ }^{1}$ Encouraging medical students and postgraduate trainees to engage in research projects is an activity that should be given high priority. ${ }^{2,3}$

In this commentary we offer the perspectives of a student who has had recent experience with publication ${ }^{4-6}$ and a senior clinician-researcher who has guided several medical students and residents through the process..$^{7-10}$ Although as a father and son we have not previously written a paper together, we have exchanged many stories about our successes and failures and those of our peers, an advantageous and ongoing learning opportunity that we both have enjoyed. We therefore offer advice for both students (summarized in Box I) and mentors (Box 2).

\section{The student's advice}

First, a commitment to do a research project must be made. Balancing medical school and a social life can be a challenge, and adding another activity will make considerable demands on your time. If you decide to do a project, acknowledge that this is something you are willing to carry through to completion, which may take years. Taking on a project that becomes more complex or demanding than one imagines is an error common among first-time researchers. If a smaller, less ambitious project presents itself, that may be a more appropriate first attempt at research.

Second, find a project in an area of interest to you. Start by considering the papers you enjoyed reading outside of the required curriculum. Do not take on a project simply because a faculty member you approached suggested it and you do not want him or her to feel offended. Think twice before saying "yes" to the first idea floated.

Next, you must seek out a supervisor. In doing so, it is imperative that you "research the researcher" before you take on a project. Asking others who have worked with the supervisor is a great option. Stay away from those who take weeks to respond to questions, review protocols or provide comments on drafts of manuscripts. Because students often feel intimidated, this situation is a difficult one. Look for supervisors

Box 1: Advice for students

- Be aware of the scope of your research project, including its length - will it take months or years to complete?

- Choose a smaller project rather than one that will be (or looks likely to become) complex and demanding

- Make a personal commitment to finish the research

- Choose an area of interest to you, irrespective of other pressures and suggestions

- Research your potential research advisor

- What is her or his track record on grants and publications with other student coauthors?

- Has he or she been responsive and supportive to previous students? If so, were the responses timely?

- Make contingency plans for things that may go wrong

- Stay in touch: communicate often with team members

- Coordinate with your teammates to guarantee a single "hot copy" or active draft of the paper, to avoid developing parallel versions

- Back up your data regularly; store a copy offsite

- If you find that research is not your "thing," investigate other means to achieve your career goals 
who have a good track record in supporting their students' projects in a timely fashion with resulting publications.

I (M.E.D.) have been very fortunate with my supervisors, but this is not a coincidence. I chose supervisors who are finishers. I reviewed their grant and publication histories before starting the projects. Therefore, I had faith in their talents. One supervisor stands out. ${ }^{4} \mathrm{He}$ inspires me with every meeting. He always has a clear sense of what he wants to do with the project. He is creative and comes up with good ideas. Most importantly, he knows how to finish the job by getting through those last few yet critical steps before publishing, which can sometimes be the death knell for perfectly publishable manuscripts.

There is no doubt that research can be a tough grind. Problems can occur at all stages of the project: obtaining ethics approval, enrollment of subjects, gathering data for secondary analysis, managing and analyzing data, figuring out what the results mean and writing the manuscript - not to mention the many revisions! Plan for things to go wrong and, whenever possible, have a contingency plan. For example, always back your data up, because you never know when the hard drive is going to fail. Knowing that a project is going to be a long haul can help you prepare yourself. You do not want to abandon an incomplete project; this can lead to being labelled a "nonfinisher" or impose a sense of guilt.

While working on the project, always try to have a good sense of your role in the project. Communicate regularly with other members of the team about your respective tasks. Remember that senior clinicians are inherently busy, and some simply require periodic reminders. Email makes manuscript writing by teams very convenient. However, I find it very helpful to have one master copy that is controlled by one person. When many people work on multiple versions of a manuscript, it is easy to lose track of the revisions.

Finally, it is important to recognize that research is not for everyone. It is a good experience, to see if you like research; but many people may feel pressured to do it to enhance their applications for future training positions such as residency. For those not inclined toward research, less painful means might be found.

That being said, there is a tremendous sense of accomplishment when a paper is published. You know that your peers throughout the world have a chance to read it and, hopefully, change their practices based on your findings. That is the foremost goal of clinical research.

\section{The faculty member's advice}

The research process can be divided into 3 stages: the planning stage, the execution stage and peer-review. Planning begins with an idea or question. Begin by getting to know something about your student's background. Is there an area of interest already defined? Have they done research before? If so, how did it go? What are the reasons for wanting to do a project? Although one of the easiest paths is to give a student one of your own research questions, the student may feel an obligation to participate in a project of no interest to him or her. (Remember, students may not be willing to tell you the truth if they feel it will disappoint you.) In that case, the proj-

\section{Box 2: Advice for faculty members}

- Get to know your student, including areas of interest and previous experiences with research

- Encourage input from the student on the research topic - Is the research question answerable within the student's ability to make a genuine authorship contribution?

- Will the student be available for the period required?

- Is she or he interested and motivated enough to finish the project?

- Ensure that roles, timelines and milestones are explicit from the outset

- Discuss authorship order at the outset and how it will be linked to performance

- Exercise judgment in the timing and dispensing of advice

- Provide the resource connections and information of which the student is unaware

- Share your knowledge of the publication process. Since no paper will ever be perfect, discuss:

- How one might judge when adequate time has been spent in preparation and revision

- How authors should receive and respond to criticisms and directives from peer reviewers

ect is unlikely to succeed. For students unable to generate their own research question, try to sense when the student is less than enthused by an idea and suggest alternative ones.

For students who wish to pursue their own questions, I ask them to prepare a list of 3 or 4 . In choosing one, the most important issue is whether the project can be completed. The questions I usually ask include: Is the research question answerable? Can it be done in a reasonable time frame for a student (no more than 2 and a half years)? Can the student and I control the issues such as data access or availability of equipment or staff to perform the study? Overall, I try to make sure that the question is focused to ensure the project will come to fruition. And remember, the project must be submitted for ethics approval early; otherwise, it can delay the start beyond the point where a student is available.

Examples of projects performed by students or residents under my supervision that have led to completion include surveys,${ }^{7,8}$ secondary analyses of other data ${ }^{10}$ and primary data collection where it was clear from the outset that we could have access to the subjects. ${ }^{9}$ A key point for the student is to be able to claim intellectual ownership, so a smaller project may be a much better choice than a large-scale one.

Students often ask, "How do I hit the home run - how do I get a paper in JAMA or NEJM?" I tell them that having a good question is important, but what gets a paper into a top journal is not the question, but rather the answer. Since you do not know the answer before performing the study, it is nearly impossible to predict which projects will be "home runs."

For a mentor, the execution of a project entails perseverance, availability, help with problem-solving, and appropriate advice given at the right times. Many students start projects; fewer finish them. No single approach works with all students. Sometimes I let the student determine the time frames, with gentle 
(or more vigorous) reminders, and at other times I am very prescriptive about timelines. Occasionally, I ask the student to pass the project onto someone else if the delay has been excessive.

Whatever approach you take, it is important to set up explicit expectations for all members of the team from the outset on roles, timelines and milestones. A useful mechanism is to propose submission of an abstract for presentation at a scientific meeting; this gives the student a target date. Also from the outset, authorship and author order should should be explicitly discussed and linked to expectations of performance.

The supervisor's role is also one of helping the students with problem-solving. Sometimes, this means making the right connections to resources are required to complete the project. ${ }^{7}$ One example might be access to a statistician. At other times it is simply deriving a solution that the student could not possibly know exists. A fundamental rule I use is that, in the process of research, anything that can go wrong, will: the mice will die, the freezer power will go off, the mailed survey will be returned for insufficient postage, the original angiograms that the editor asked for will get lost in the mail. ${ }^{3}$ Research that reaches completion always involves excellent problem-solving skills.

A supervisor's advice can be invaluable, but judgment must be exercised in providing it. Some supervisors actually perform the project for the student; I do not think this is best. Sometimes, however, it is frustrating to watch a student do something over 3 weeks that would take me half an hour to accomplish. The supervisor must also exert judgment as to how much improving the paper needs before submission to a journal, because no paper will ever be perfect. In the end, I try to get my students to focus on the objective of "putting the puck in the net."

The last step is giving advice about peer-review. Authors must not take reviews personally! The best way to handle peerreview is to read the comments once and then sleep on them. Read again the next day, they will cause much less anger. If you are resubmitting to the same journal, the team must address all suggestions (but not necessarily make every change that was requested). Give your student a well-crafted reply letter from one of your previous papers to use as an example, and ask him or her to take a first crack. When a paper is rejected, I read the reviews but only make changes where I completely agree. Since all reviews are subjective, there is no point in making changes for someone who will not see it again.

\section{The bottom line}

Here are our most important messages. For the student, pick a supervisor who is a timely finisher, and choose a project you like (both the topic and the "nuts and bolts" of it). For the supervisor, make sure the student wants to do the project and stress the importance of perseverance through the problems to get to the fun parts. Good luck!

This article has been peer reviewed.

Michael Detsky and Allan Detsky are with the University of Toronto, Toronto, Ont.

Competing interests: None declared.

Contributors: Both authors contributed to the writing and critical revision of the article and approved the final version for publication.

Acknowledgements: We thank Jay Rosenfield, Jenny Heathcote, Donald Redelmeier and David Juurlink (all, University of Toronto) for their helpful comments and suggestions.

\section{REFERENCES}

I. Nathan DG; National Institutes of Health Director's Panel on Clinical Research. Clinical research: perceptions, reality, and proposed solutions. JAMA I998;280: I427-3I.

2. Gonzales AO, Westfall J, Barley GE. Promoting medical student involvement in primary care research. Fam Med I998;30:II3-6.

3. Rivera JA, Levine RB, Wright SM. Brief report: completing a scholarly project during residency training. Perspectives of residents who have been successful. J Gen Intern Med 2005;20:366-9.

4. Detsky ME, Sivilotti MLA, Kopp A, et al. Deliberate self-poisoning in Ontario following the terrorist attacks of September II, 200I. JAMA 2005;294:I900-I.

5. Detsky ME, Chiu L, Shandling MR, et al. Heading down the wrong path. $N$ Engl Med 2006;355:67-74.

6. Detsky ME, McDonald DR, Baerlocher MO, et al. Does this patient with headache have a migraine or need neuroimaging? JAMA 2006;296:1274-83.

7. Stelfox HT, Chua G, O'Rourke K, et al. Conflict of interest in the debate over calcium-channel antagonists. $N$ Engl J Med I998;338: IoI-6.

8. McCormick BB, Tomlinson G, Brill-Edwards P, et al. Effect of restricting contact between pharmaceutical company representatives and internal medicine residents on posttraining attitudes and behaviour. JAMA 200I;286:I994-9.

9. Booth C, Matukas LM, Tomlinson GA, et al. Clinical features and short-term outcomes of I44 patients with SARS in the Greater Toronto Area. JAMA 2003;289:280I-9.

Io. Bagai A, Thavendiranathan P, Detsky AS. Does this patient have hearing impairment? JAMA 2006;295:4I6-28.

Correspondence to: Dr. Allan Detsky, Department of Medicine, Mount Sinai Hospital, 600 University Ave., Suite 427, Toronto ON M5G IX5; fax 416 586-8350; allan.detsky@uhn.on.ca 